\title{
Sigil Software sebagai Pengembangan E-Modul Pembelajaran Matematika
}

\author{
Anisa Fitri ${ }^{1}$, Netriwati ${ }^{2}$, Siska Andriani ${ }^{3}$ \\ ${ }^{1,2,3}$ Progam Studi Pendidikan Matematika, UIN Raden Intan Lampung, Indonesia \\ *anisa97.af@gmail.com
}

\begin{abstract}
ABSTRAK
Kesulitan yang dialami mahasiswa untuk mempelajari matematika disebabkan oleh kurang praktis dan kurang menariknya media yang digunakan oleh dosen dalam pembelajaran matematika. Hal tersebut mengakibatkan hasil belajar mahasiswa menjadi rendah khususnya materi relasi dan fungsi. Tujuan dari penelitian ini yaitu untuk mengetahui kelayakan dan respon mahasiswa terhadap rancangan perangkat pembelajaran e-modul matematika dengan menggunakan sigil software. Jenis penelitian ini yaitu Research \& Development $(R \& D)$ menggunakan model ADDIE. Teknik pengumpulan data menggunakan teknik wawancara, kuisioner dan tes. Validasi dilaukukan oleh tiga ahli materi dan dua ahli media. Hasil validasi menunjukkan $e$-modul layak digunakan karena sudah baik dalam hal kelayakan isi, kebahasaan, dan penyajian. E-Modul hasil revisi diujicobakan pada uji skala kecil (10 mahasiswa) dan dilanjutkan uji skala besar (28 mahasiswa). Respon mahasiswa terhadap $e$-modul juga mendapat nilai tinggi pada semua indikator. Sehingga e-modul yang telah dikembangkan menjadi layak dan efektif, dapat digunakan dalam proses pembelajaran matematika.
\end{abstract}

Kata kunci: Pengembangan E-Modul, Sigil Software.

\begin{abstract}
Difficulties experienced by students to learn mathematics caused by the lack of practical and less interesting media used by lecturers in learning mathematics has an impact on the low student learning outcomes, especially in the matter of relations and functions. Therefore, this study aims to determine the feasibility and response of students to the design of mathematics e-module learning devices using sigil software. This type of research is Research $\&$ Development (R\&D) using the ADDIE model. Data collection techniques using interview techniques, questionnaires and tests. Validation was carried out by three material experts and two media experts. The validation results show that the e-module is suitable for use because it is good in terms of content, language, and presentation feasibility. The revised E-Module was tested on a small-scale test (10 students) and continued with a large-scale test (28 students). Student responses to e-modules also scored high on all indicators. It can be concluded, the emodule that has been developed is feasible and effective for use in the mathematics learning process.
\end{abstract}

Key words: Modul elektonik, Sigil Sofware.

Received: 2020-09-03

/ Accepted: 2021-04-14

/ Published: 2021-05-01

\section{Pendahuluan}

Sesuai perkembangan teknologi, pemanfaatan teknologi dalam dunia pendidikan kini sangat dibutuhkan didalam proses pembelajaran. Dengan teknologi peluang terciptanya berbagai inovasi alat pembelajaran untuk pendidikan semakin besar. J.R. Carreon (2018) menjelaskan bahwa teknologi memiliki kontribusi yang sangat berharga dan dianggap sebagai masa depan pendidikan karena menciptakan peluang untuk pengembangan dan inovasi perangkat pembelajaran diberbagai institusi.

Untuk meningkatkan keterampilan mahasiswa diperlukan adanya perubahan untuk menunjang proses pembelajaran matematika ditingkat perguruan tinggi khususnya materi relasi dan fungsi. Oleh karena itu dibutuhkan media pembelajaran yang praktis dengan memanfaatkan teknologi yang dapat diakses kapanpun dan dimanapun sehingga bisa menarik minat mahasiswa terhadap pembelajaran matematika. Daryanto (2012) berpendapat bahwa manfaat media secara umum, yaitu dapat membuat pembelajaran lebih interaktif, menarik, mengurangi jumlah waktu 
mengajar, dapat meningkatkan kualitas belajar mahasiswa, dan fleksibel yaitu dapat dilakukan dimanapun dan kapanpun serta bisa meningkatkan sikap belajar siswa.

Hasil wawancara penulis dengan dosen prodi pendidikan matematika UIN Raden Intan Lampung, diperoleh informasi yaitu dijurusan pendidikan matematika UIN Raden Intan Lampung masih kurang media pendukung pembelajaran, sehingga dosen mengajar menggunakan buku ajar dan power point. Namun demikian dosen lebih sering menggunakan buku ajar dikarenakan terbatasnya jumlah proyektor untuk menampilkan power point. Akibat dari kurangnya media pembelajaran ini menyebabkan pencapaikan tujuan pembelajaran kurang maksimal. Penulis juga menyebarkan angket kepada beberapa mahasiswa UIN Raden Intan Lampung, UM Metro dan STKIP PGRI Bandar Lampung, diperoleh informasi dari angket bahwa mahasiswa cenderung merasa bosan karena media pembelajaran yang monoton dan kurang praktis.

Dosen yang profesional adalah dosen yang mempunyai seni mendidik dan daya kreatifitas yang tinggi, sehingga bisa membuat inovasi dalam proses pembelajaran yang menciptakan kenyamanan mahasiswa dalam menikmati proses pembelajaran yang berlangsung. Dengan jiwa seni dan kreatifitas yang tinggi dosen dapat mengarahkan mahasiswa untuk menggunakan media pembelajaran berupa $e$-modul. Menggunakan $e$-modul dapat meningkatkan kemampuan psikomotorik mahasiswa. Materi didalam E-Modul hanya ada satu materi pembelajaran saja dan $e$-modul bersifat self-instructional yang artinya $e$-modul ini mengutamakan kemandirian mahasiswa dalam penggunaannya. Dalam proses pembelajran menggunakan modul elektroni (e-modul) ini mahasiswa tidak hanya mengandalkan atau bergantung pada dosen untuk mendapatkan sumber informasi, dengan begitu akan tercipta pembelajaran yang interaktif. Selain itu kelebihan dari penggunaan modul elektronik ini yaitu mendukung gerakan Go Green dalam upaya menyelamatkan pohon sebagai bahan baku pembuatan kertas karena modul elektronik tidak harus diproduksi secara cetak sehingga menghemat pemakaian kertas untuk mencetak buku pembelajaran.

Pemanfaatan software pada pembelajaran matematika saat ini telah banyak dilakukan, salah satunya yaitu Sigil Sofware. Sigil adalah software editor untuk epub yang bersifat open source. E-modul berbantuan Sigil Sofware ini juga dapat mempermudah mahasiswa dalam mempelajari materi pembelajaran, sedangkan peran dosen hanya sebagai fasilitator sehingga dosen tidak perlu ceramah untuk menyampaian materi secara keseluruhan, dengan begitu dosen dapat menghemat tenaga dan waktu. Media pembelajaran tersebut dapat mempermudah mahasiswa dalalm memahami materi belajar terutama materi yang bersifat abstrak. Agar pembelajaran berjalan dengan baik selama proses belajar menggunakan e-modul bebantuan Sigil Sofware mahasiswa perlu diberikan bekal dan informasi yang memadai mengenai penggunakan $e$-modul tersebut. Karena sangat berpengaruh terharap keberhasilan hasil belajar.

Beberapa penelitian menunjukkan bahwa pengembangan media pembelajaran e-modul berbantuan sigil software efektif digunakan dalam proses pembelajaran. Salah satu dari penelitin tersebut yaitu F. Amalia (2017) mengungkapkan bahwa "e-book Fisika menggunakan Sigil diterima dengan baik oleh siswa dan dapat dipergunakan dalam pembelajaran Fisika untuk melatihkan keterampilan berpikir kritis siswa”. Selain itu (Maharani, 2015) menyatakan bahwa: "pemakaian software Sigil sebagai software pembuat media pembelajaran yang memiliki nilai ekonomis bagi kalangan pelajar. ". Penelitian yang dilakukan oleh (Daud, 2019) menyatakan, "pengembangan perangkat pembelajaran dengan menggunakan software sebagai salah satu perangkat pembelajaran matematika yang memenuhi kriteria valid, praktis, dan efektif". 


\section{AlphaMath \\ Journal of Mathematics Education, 7(1) May 2021}

Berdasarkan kondisi tersebut maksud dari penelitian ini yaitu untuk membuat inovasi media pembelajaran berupa $e$-modul dengan berbantuan sigil software.

Rumusan masalah yang didapat dari paparan di atas yaitu; bagaimana proses pengembangkan e-modul berbantuan Sigil Software pada materi relasi dan fungsi, bagaimana respon mahasiswa dan dosen terhadap e-modul berbantuan Sigil Software pada materi relasi dan fungsi, apakah $e$ modul berbantuan Sigil Software pada materi relasi dan fungsi efektif untuk diterapkan sebagai media pembelajaran.

Tujuan pembelajaran pada penelitian ini dengan berdasarkan rumusan masalah tersebut yaitu mengetahui bagaimana proses pengembangkan e-modul berbantuan Sigil Software pada materi relasi dan fungsi, mengetahui bagaimana respon mahasiswa dan dosen terhadap e-modul berbantuan Sigil Software pada materi relasi dan fungsi, dan mengetahui apakah e-modul berbantuan Sigil Software pada materi relasi dan fungsi efektif untuk digunakan dalam proses pembelajaran.

\section{Metode Penelitian}

Penelitian ini menggunakan metode penelitian dan pengembangan atau Research and Development (RnD). Dalam Richey dan Klein (2007), Research and Development adalah pengamatan yang sistematis tentang cara merancang suatu produk, memproduksi atau mengembangkannya. Tujuannya yaitu agar mendapatkan data yang empiris dan bisa dipergunakan sebagai landasan atau dasar dalam membuat alat, produk dan modul yang dapat diterapkan dalam proses pembelajaran maupun non pembelajaran.

Model dalam penelitian ini adalah model pengembangan Robert Maribe Brch yaitu ADDIE yang terdiri dari 5 tahapan diantaranya tahap Analysis (Analisis), Design(Perancangan), Development (Pengembangan Rancangan), Implementation (Penerapan), dan Evaluation (Evaluasi). Sugiono (2015) mengemukakan bahwa Penelitian dan pengembangkan adalah proses atau metode dalam mengembangkan dan memvalidasi produk seperti film pembelajaran, buku, program pendidikan, software, dan metode mengajar.

Subjek penelitian yaitu individu, benda atau organisme yang menjadi sumber informasi yang diperlukan dalam penelitian. Subjek dalam penelitian ini meliputi mahasiswa semester II di UIN Raden Intan Lampung.

Teknik pengumpulan data pada penelitian ini yaitu teknik wawancara, angket dan tes. Wawancara dilakukan saat pra penelitian untuk mengetahui kebutuhan dosen dan mahasiswa. Tes dalam penelitian ini yaitu melakukan Pretest diawal pembelajaran kemudian melakukan Posttest diakhir pembelajaran kepada mahasiswa, angket dalam penelitian ini untuk mengetahui respon ahli materi, ahli media, dan mahasiswa mengenai pengembangan media pembelajaran e-modul menggunakan sigil Software serta mengetahui kelayakan produk sebagai dasar untuk merevisi produk. Bentuk dari angket ini menggunakan skala Likert seperti terangkum dalam Sugiono (2015).

Menjawab permasalahan ini sesuai dengan tujuan penelitian untuk mengetahui kelayakan media pembelajaan e-modul berbantuan sigil software untuk mahasiswa dan dosen UIN Raden Intan Lampung. Hal tersebut dapat diketahui dengan menggunakan lembar validasi ahli media 
dan lembar validasi ahli materi yang dinilai oleh dua validator ahli media dan tiga validator ahli materi.

Tabel 1. Interpretasi skor kelayakan

\begin{tabular}{cc}
\hline Skor & Pilihan jawaban Kelayakan \\
\hline 4 & Sangat Baik \\
3 & Baik \\
2 & Kurang Baik \\
1 & Sangat kurang baik \\
\hline
\end{tabular}

Tabel 2. Kriteria effect size

\begin{tabular}{cc}
\hline Penilaian & Kiteria \\
\hline ES $\leq 0,20$ & Rendah \\
$0,20<$ ES $\leq 0,80$ & Cukup \\
ES $>0,80$ & Tinggi \\
\hline
\end{tabular}

Keefektifan penggunaan media e-modul berbantuan sigil software di UIN Raden Intan Lampung pada penelitian ini dapat diketahui dengan cara memberikan 5 soal pretest dan 5 soal posttest ke mahasiswa, kemudian dihitung mengunakan analisis effect size menurut Nurhayati (2014). Dikatakan efektif berdasarkan kriteria effect size apabila hasil perhitungan pretest dan posttest mahasiswa masuk dalam kategori minimal sedang.

\section{Hasil dan Pembahasan}

Hasil penelitian ini didapatkan dari proses analisis kebutuhan, perancangan dan pembuatan media pembelajaran. Data hasil penelitian dan pengembangan e-modul berbantuan sigil software secara ringkas yaitu sebagai berikut:

\section{Kelayakan Media Pembelajaran}

Untuk mengetahui kelayakan media pembelajaran sebelum diujicobakan di lapangan maka terlebih dahulu dilakukan validasi produk. Peneliti menggunakan 3 ahli materi dan 2 ahli media dalam proses validasi. Validasi media dilakukan penilaian terhadap e-modul berbantuann sigil software dengan berdasarkan sudut pandang terhadap media tersebut. Sedangan validasi ahli materi yaitu dengan melakukan penilaian terhadap kesesuaian materi yang terdapat didalam media e-modul berbantuan sigil software apakah telah sesuai atau belum.

Tahap validasi media dan validasi materi diakukan agar produk e-modul berbantuan sigil software yang dikembangkan dianggap layak oleh para ahli sehingga dapat diujicobakan kepada mahasiswa. Selain hal tersebut tahap validasi ahli dibutuhkan untuk mengetahui adanya kesalahan dan kekurangan materi maupun kurang menariknya media saat ujicoba lapangan. Selain produk didesainkan, desain produk tersebut diserahkan kepada validator untuk divalidasi dan dinilai kelayakannya.

\section{Validasi media}

4 | $\begin{aligned} & \text { C2021 by Department of Mathematics Education, UMP, Purwokerto, Indonesia } \\ & \text { p-ISSN 2477-409X, e-ISSN: 2549-9084 and website: http://jurnal nasional.ump.ac.id/index.php/alphamath/ }\end{aligned}$ 
Hasil dari validasi media sebagai berikut:
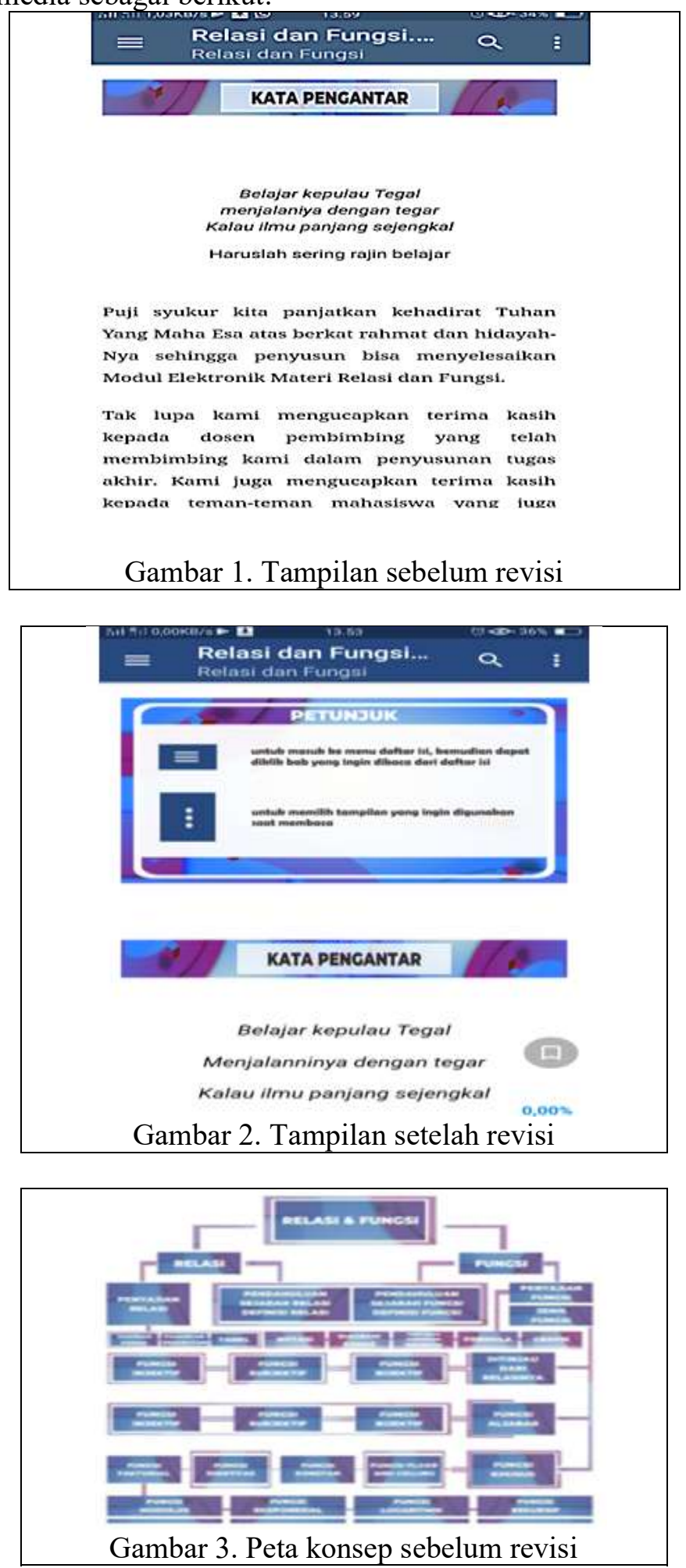

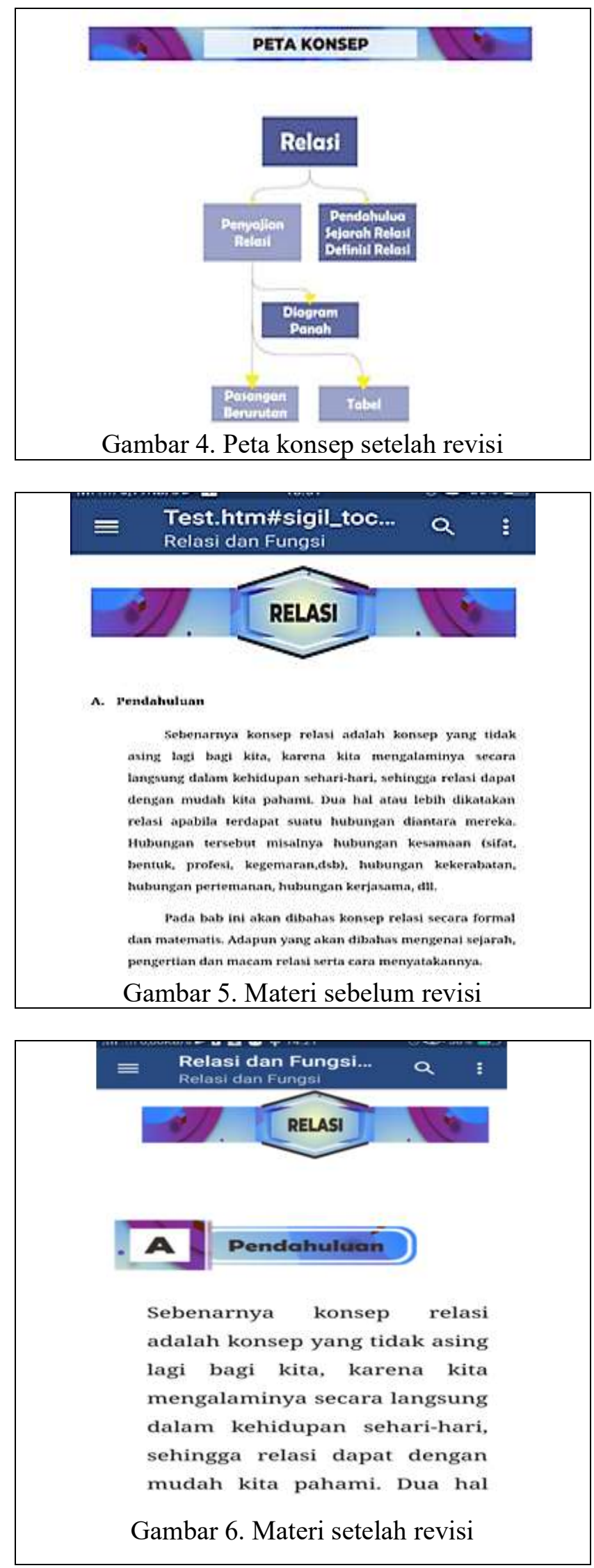
Validator ahli media dalam penelitian pengembangan e-modul dengan berbantuan sigil software yaitu 2 dosen yang ahli di bidang media. Penilaian yang dilakukan oleh ahli media pada media e-modul ini sebanyak dua kali penilaian dilakukan secara keseluruhan dengan pembenaran konsep dan melihat keterampilan media pada aspek pembelajaran. Setelah tahap validasi dilakukan kemudian diketahui bahwa masih ada kekurangan dan dibutuhkan perbaikan media dari penilaian ahli tahap pertama terhadap e-modul berbantuan sigil software.

Setelah mendapatkan hasil penilaian tahap pertama dari ahli media, kemudian produk direvisi sesuai dengan masukan dari para ahli dengan tujuan yaitu media bisa menjadi lebih baik dari sebelumnya. Media diperbaiki dengan saran validator dan berdasarkan hasil penilaian dari validator ahli media. Setelah perbaikan produk selesai langkah selanjutnya yaitu validasi produk tahap kedua. Berdasarkan penilaian validator pada tahap kedua produk yang dikembangkan dinyatakan layak oleh ahli media dan dapat diujicobakan dilapangan. Hasil penilaian validasi media tahap pertama dan tahap kedua mengalami peningkatan seperti terlihat pada gambar 7 .

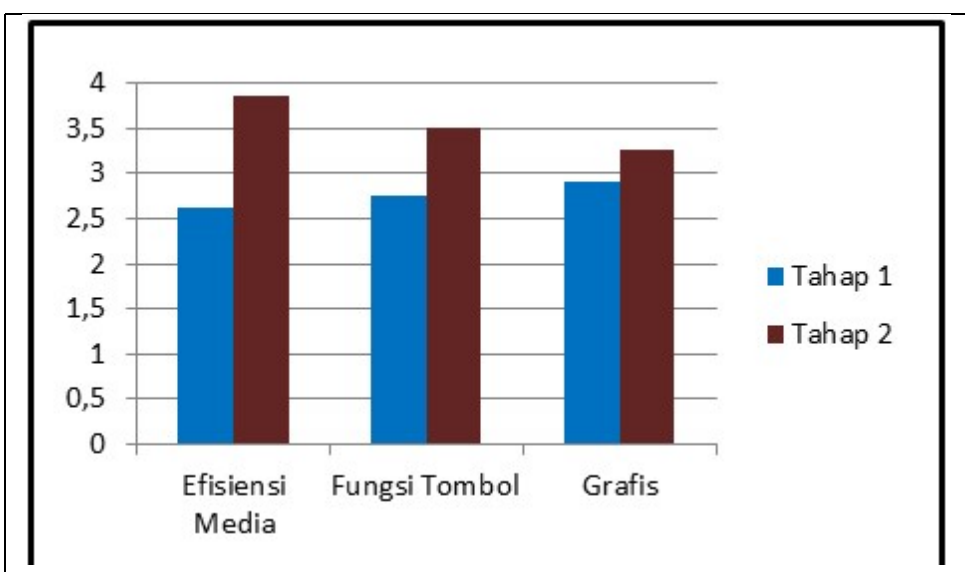

Gambar 7. Perbandingan validasi ahli media 1 dan 2

\section{Validasi Materi}

Validator ahli materi dalam penelitian ini yaitu tiga orang dosen mata kuliah matematika yang ahli dalam bidang validasi materi. Validasi materi dilakukan dengan memperlihatkan dan mempresentasikan produk dan memberikan angket penilaian sebanyak tiga lembar. Setelah mendapatkan hasil dari validator, diketahui bahwa masih banyak kesalahan penulisan dan kekurangan didalam materi. Selanjutnya e-modul direvisi dengan melihat penilaian para ahli. Setelah selesai direvis produk kemudian divalidasi lagi pada tahap kedua. Hasil validasi tahap kedua terhadap e-modul berbantuan sigil software dikatakan layak oleh para ahli.

Hasil penilaian validasi materi tahap pertama dan tahap kedua mengalami peningkatan seperti pada terlihat pada gambar 8 dibawah ini: 


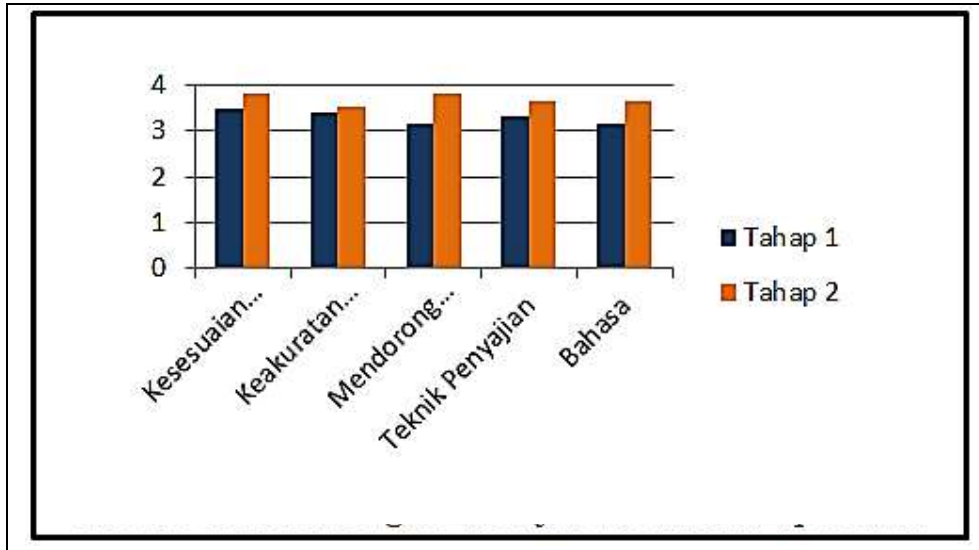

Gambar 8. Perbandingan hasil uji ahli materi tahap 1 dan 2

\section{Uji Kemenarikan}

Uji kemenarikan produk pada penelitian ini yaitu dengan uji coba skala kecil dan uji coba skala besar. Skala Kecil meliputi 10 responden pada mahasiswa semester II. Hasil uji coba skala kecil mendapatkan nilai rata-rata 3,43 dengan kriteria Sangat Menarik. Diperoleh kesimpulan bahwa e-modul berbantuan sigil software yang dikembangkan layak digunakan selama proses pembelajaran. Selanjutnya yaitu uji coba skala besar yang melibatkan 28 responden pada semester II untuk mengetahui kemenarikan e-modul secara luas. Hasil analisis data uji skala besar pada semester II yaitu 3,58 pada kriteria Sangat Menarik. Data hasil uji kemenarikan skala kecil dan skala besar terlihat pada gambar 9 dibawah ini:

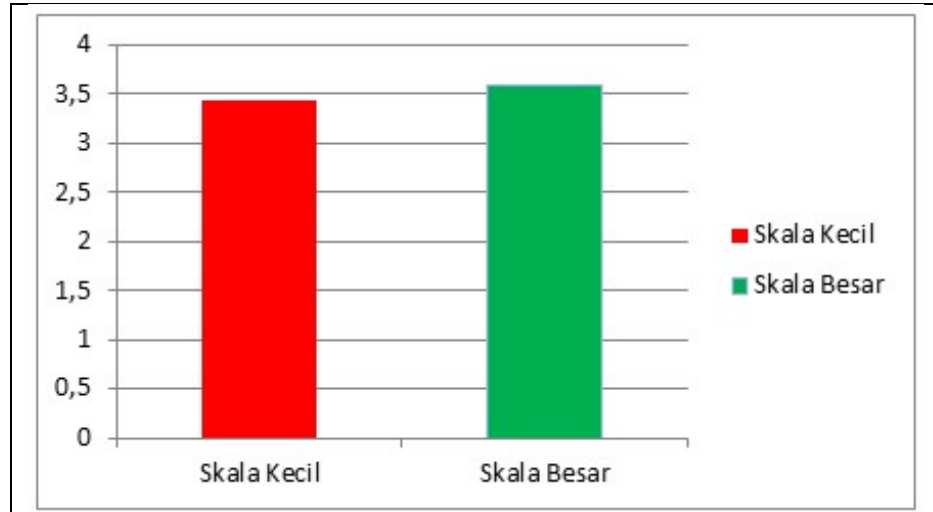

Gambar 9. Grafik perbandingan Uji Kemenarikan

Keefektifan e-modul dengan berbantuan sigil sofware dapat dilihat setelah mahasiswa menggunakan media pembelajarn e-modul berbantuan sigil sofware. Berikut klasifikasi kriteria effect size: 
Tabel 3. Kategori Effect Size

\begin{tabular}{cc}
\hline Nilai $\mathrm{d}$ & Kategori \\
\hline $0,8 \leq \mathrm{d} \leq 2,0$ & Tinggi \\
$0,5 \leq \mathrm{d}<0,8$ & Sedang \\
$0,2 \leq \mathrm{d}<0,5$ & Rendah \\
\hline
\end{tabular}

Dari pretest dan posttes yang dilakukan peneliti diperoleh data hasil tes mahasiswa sebagai berikut:

Tabel 4. Data Hasil Perhitungan Pretest dan Posttest

\begin{tabular}{cccccc}
\hline & N & $\begin{array}{c}\text { Skor } \\
\text { Maksimum }\end{array}$ & $\begin{array}{c}\text { Skor } \\
\text { Minimum }\end{array}$ & Rata-Rata & $\begin{array}{c}\text { Standar } \\
\text { Deviasi }\end{array}$ \\
\hline Pretest & 28 & 60 & 20 & 45 & 42,51 \\
Posttest & 28 & 90 & 60 & 73,75 & 72,20 \\
\hline
\end{tabular}

Dari Hasil analisis data pada tabel 4 diketahui bahwa nilai rata-rata posttest lebih besar dari nilai rata-rata pretest, dan standar deviasi nilai posttest lebih besar daripada standar deviasi nilai pretest. Hasil uji effect size yaitu diperoleh $E_{s}=0,52$ kategori sedang. Yang artinya rata-rata hasil belajar mahasiswa setelah menggunakan e-modul lebih tinggi daripada rata-rata hasil belajar mahasiswa sebelum menggunakan $e$-modul. Dari kesimpulan tersebut dapat dikatakan bahwa e-modul berbantuan sigil software dapat meningkatkan kemampuan hasil belajar mahasiswa

\section{Simpulan}

Produk yang dihasilkan dari penelitian dan pengembangan ini yaitu E-modul. Pengembangan produk ini dilakukan dengan mengacu pada rancangan penelitian dan pengembangan dari model ADDIE. Berdasarkan hasil uji coba produk dan pembahasan, dapat ditarik kesimpulan bahwa e-modul berbantuan sigil software layak digunakan dan diterapkan sebagai media pembelajaran dengan rata-rata skor ahli materi 3,70 dan ahli media 3,54. Hasil uji effect size dengan skor $E_{S}=0,52$ menunjukkan bahwa e-modul yang dikembangkan efektif digunakan sebagai media untuk membantu proses pembelajaran.

\section{Daftar Pustaka}

Amalia, F., \& R Kustijono.(2017). Efektifitas Penggunaan E-Book Dengan Sigil Untuk Melatihkan Kemampuan Berpikir Kritis. Seminar Nasional Fisika (SNF), 84.

Arda, dkk. (2015). Pengembangan Media Pembelajaran Interaktif Berbasis Komputer unttuk Peserta Didik. Jurnal Mitra Sains, 33(1)

Arsyad, Azhar. (2015). Media Pembelajaran. PT RajaGrafindo Persada. Jakarta.

Daud, Rusgianto Heri Santoso. (2019). Pengembangkan Perangkat Pembelajaran Menggunakan Software Cabri 3D Materi Bangun Ruang Sisi Datar Dengan Metode Problem Solving Yang Berorientasi Pada Kemampuan Berpikir Kritis Dan Prestasi Belajar Siswa SMP. AlphaMath : Journal of Mathematics Education, 5(1), 1. 
Daryanto. (2012). Media Pembelajaran. PT Sarana Tutorial Nurani Sejahtera. Bandung. Depdiknas. (2003). Undang-Undang RI NO 20 tahun 2003 . tentang sistem pendidikan nasional.

Fausih, Moh, and T Danang. (2015).Pengembangan Media E-Modul Mata Pelajaran Produktif Pokok Bahasan Instalasi Jaringan Lan (Local Area Network ) Untuk Siswa Kelas Xi Jurusan Teknik Komputer Jaringan Di SMK Nengeri 1 Labang, Bioedukasi, 1(1), 1.

Hess, Amanda Nichols., \& Katie Greer. (2016).Designing for Engagement :Using the ADDIE Model to Integrate High-Impact Practices into an Online Information Literacy Course Designing for Engagement : Using the ADDIE Model to Integrate High-Impact Practices into an Online Information Literacy Course'. Communications In Information Literacy.

Hidayat, Rahmat and others.(2017).Pemanfaatan Sigil Untuk Pembuatan E-Book (Electronic Book ) Dengan Format EPub EPuB. TEKNOSI, 3(1), 2.

J. R. Carreon. (2018). Facebook as integrated blended learning tool in technology and livelihood education exploratory. International Journal of Educational Technology. 5(2), 19.

Maharani, Pangestuning., Febrianto Alqodri, \& Rony Aldhea. (2015). Pemanfaatan Software Sigil Sebagai Media Pembelajaran E-Learning Yang Mudah, Murah Dan User. Seminar Nasional Teknologi Informasi dan Multimedia, 2.

Nurhayati, Syarifah Fadilah, M Mutmainah. (2014). Penerapan Metode Demonstrasi Berbantu Media Animasi Software Phet Terhadap Hasil Belajar Siswa Dalam Materi Listrik Dinamis Kelas X Madrasah Aliyah Negeri 1 Pontianak. JPFA : Journal of Physics Research and Its Aplication, 4(2).

Nuryadi, Zulfa Hanani Bahtiar. Pengembangan Media Pembelajaran Matematika Interaktif Menggunakan Adobe Flash Cs 5 Pokok Bahasan Trigonometri Untuk Meningkatkan Motivasi Belajar Siswa Kelas X Sma. AlphaMath: Journal of Mathematics Education, $3(1), 4$.

Richey, Rita C. and Klein, James.D. (2007). Design and Development Research: Methods, Strategies, and Issues. Lawrence Erlbaum Associates, Publihers. Mahwah, New Jersey.

Sanjaya, Wina. (2013). Peneitian Pendidikn Jenis, Metode, dan Prosedure. Prenada Media Group. Jakarta.

Sugiono. (2015). Metode Penelitian dan Pengembangan. Alfabeta. Bandung.

Suratman, Dede. (2019). Pengembangan Bahan Ajar Interaktif Untuk Perolehan Keterampilan Menentukan Luas Daerah Yang Dibatasi Dua Fungsi. Jurnal Pendidikan Matematika dan IPA (JPMIPA), 10(2), 219.

Syahroni, Moh., Nurrochmah, Siti, \& Fahrial Amiq. (2016). Pengembangan Buku Saku Elektronik Berbasis Android Tentang Signal-Signal Wasit Futsal Untuk Wasit Futsal Di Kabupaten Pasuruan, Jurnal Jasmani, 26(2), 304-317 